\title{
O DESPERDÍCIO DA
}

EXPERIÊNCIA E DA FONTE DE OBSERVAÇÃO ÚLTIMA DO PROFETA SOFONIAS EM CONTEXTO COM AS ALIANÇAS DIVÍNAS E OS ELEMENTOS REDENTIVOS DE UM REINO VINDOURO

THE WASTE OF THE PROPHET'S SOPHONY EXPERIENCE AND SOURCE OF OBSERVATION IN CONTEXT WITH THE DIVINE ALLIANCES AND REDEMPTIVE ELEMENTS OF A WINE KINGDOM

\section{Idílio Oliveira de Akaújo ${ }^{88}$}

88 Bacharel em Direito pela UNICAP; Pós Graduado pela Escola Superior da Magistratura .PE; Especialista em Direito Penal e Processual Penal com Magistério Superior pela SCES Inniversidade Federal de Pernambuco; Pós graduado pela Universidade de Coimbra, Portugal em Direito Penal Econômico e Europeu; Doutorando pela Universidad Del Museo Social Argentino, Buenos Aires em Ciências Jurídicas e Sociais; Bacharelando em Teologia pela Faculdade Internacional Cidade Viva/PB. Email: idiliooliveira@hotmail.com 


\section{RESUMO}

Na Teologia bíblica é comum a análise dos profetas de forma abrangente procurando fazer a exegese e interpretação do sentido de cada livro e relacioná-lo com as Boas Novas. Argumenta-se que a palavra do Profeta é a mensagem de Deus para seu povo. A partir da análise dos pactos divinos, teologicamente, desenvolvo o estudo do livro do Profeta Sofonias buscando responder as seguintes questões: Quais as alianças divinas estão sendo citadas e quais os elementos da quebra das alianças e quais as ofertas de redenção no livro do Profeta? Ainda, analiso quais os juízos pelo pecado e se existe profecia messiânica pelo novo mediador. $\mathrm{O}$ presente artigo faz uma análise estratificado das alianças divinas permeada pela limitação do livro. Ilustra-se o tema descrevendose a visão de Palmer Roberttson e o seu escólio sobre as Alianças divinas. Por derradeiro conclui-se, com enfoque nas alianças divinas, que Sofonias focaliza a necessidade de vivermos em retidão diante de Deus e que de todos os profetas, Sofonias provavelmente foi o que descreveu o juízo com mais intensidade, tendo também enaltecido a possibilidade da restauração para aqueles que se arrependessem e voltassem à retidão.

\section{PALAVRAS-CHAVE}

Sofonias. Pactos. Alianças.

\section{ABSTRACT}

In biblical theology it is common for prophets to be comprehensively analyzed to seek to exegesis and interpret the meaning of each book and relate it to the Good News. It is argued that the Prophet's word is God's message to his people. From the analysis of the divine covenants, theologically, I develop the study of the book of the Prophet Zephaniah seeking to answer the following questions: What divine covenants are being cited and what are the elements of covenant breaking and what offerings of redemption in the Prophet's book? Also, I analyze the judgments for sin and whether there is messianic prophecy by the new mediator. This article makes a stratified analysis of divine covenants permeated by the limitation of the book. The theme is illustrated by describing Palmer Roberttson's vision and his collection of divine Covenants. Finally, it is concluded, focusing on 
divine covenants, that Zephaniah focuses on the need to live righteously before God and that of all the prophets, Zephaniah probably described the judgment most strongly and also praised the possibility of restoration. to those who repent and return to righteousness.

\section{KEYWORDS}

Zephaniah. Pacts. Wedding rings

\section{INTRODUÇÃO}

A questão a ser analisada no presente artigo é: Como o livro de Sofonias se relaciona com as Alianças divinas? Porém, necessário se faz perquirir sobre o que vem a ser uma aliança divina? Como se define a relação de aliança entre Deus e seu povo? Robertson (2002) no Cristo dos Pactos, define aliança divina como um pacto de sangue soberanamente administrado.

Pois bem, o autor referido começa analisando os aspectos da definição, quais sejam: laço de sangue inviolável que une pessoas e o caráter absoluto do compromisso. Afirma que o termo - Cortar uma aliança- tem significado como penhor de morte, como invocação de uma maldição sobre si mesmo caso viole o compromisso feito. O problema mais intrigante que a teologia enfrenta hoje pode ser assim formulado: vivendo nós no pósmodernismo, num mundo líquido, como poderíamos entender o valor da aliança e o poder do sangue? A questão é: Para que o sangue? O derramamento de sangue significa o único meio de livramento das obrigações da aliança. Como entender essa afirmativa hoje?

Para o autor em foco, a morte de Cristo foi um sacrifício substitutivo. Cristo morreu no lugar do pecador por causa da violação da aliança. Seu sangue foi derramado como único meio de livramento dos pecadores das obrigações da aliança. O desconforto o conformismo ou a indignação perante a religião cristã suscita impulso para analisar a questão.

Mas, qual a extensão das alianças divinas? Nenhum período da história da redenção, de Noé a Jesus Cristo, fica fora do âmbito de tratamento por alianças de Deus com o seu povo. $O$ conceito de aliança pode ser estendido ao período precedente ao estabelecimento da aliança de Deus com Noé? Pois bem, se todos os elementos essenciais ao estabelecimento de um pacto estavam 
presentes antes de Noé, o relacionamento de Deus com o homem antes dele pode ser designado como aliança. Vejamos: Um pacto de vida e morte está claramente presente entre Deus e o homem recentemente criado; Esse relacionamento de Deus e o homem é soberanamente administrado. Outrossim, vemos em Oseias 6.7 que parece aplicar a terminologia de aliança ao relacionamento de Deus com os homens, estabelecido na criação.

E qual é a questão? Quais as alianças que estão sendo mencionadas no livro de Sofonias e quais os elementos da quebra da aliança? Quais os juízos pelo pecado e quais as ofertas de redenção? Quem são os mediadores anteriores e atuais no livro? Quem é o mediador da redenção? Existe profecia messiânica do novo mediador? Qual a abrangência desse reino? Existem elementos redentivos de um reino vindouro?

Tenho como objetivo geral analisar as alianças divinas, e para responder a essa objeção procurarei entender o que vem a ser Aliança, além de analisar os seus elementos constitutivos modelos de relacionamento entre Deus e o homem. Conceituarei aliança divina especificamente à luz da Bíblia.

Com a consciência de que nada mais prático que uma boa teoria, buscando atingir o fim pretendido com esta pesquisa, lançar-se-á mão do arcabouço teórico existente, sobremodo considerando que a discussão a respeito do tema não é rara no cenário cristão, e que não são poucas as obras que, quando não versam especificamente sobre o assunto, do mesmo se aproximam, fornecendo assim valiosos subsídios para o que se pretende.

Uma análise histórica do livro será de grande valia para que se possa conhecer das inúmeras teorias respeitantes aos mais diversos tópicos a serem abordados durante a pesquisa, como é o caso do impacto das alianças divinas no livro de Sofonias.

$\mathrm{Na}$ perspectiva cristã/teológica de análise dos diversos tópicos a serem abordados serão utilizados então os trabalhos já publicados (e os que possam vir a ser publicados até o término da pesquisa) de autoria dos já renomados autores que se debruçam sobre a pertinência do tema, bem assim de autores novos que possam surgir, o que na lista de referência aqui apresentada.

Os estudos serão realizados a partir de exames em obras de especialistas no livro de Sofonias.

Assim, analisada a doutrina no pertinente ao tema que se propõe estudar nela se buscará fazer uma incursão no que diz respeito ao aspecto conceitual, histórico-evolutivo e pragmático de 
cada um dos institutos-tópicos que, relacionados com o tema, pretende-se sejam estudados, com ênfase nas alianças divinas.

Para a consecução do trabalho proposto, será elaborada pesquisa quantum satis na literatura geral a fim de se perquirir e dela se pode extrair elementos de conclusão, o que se fará a partir de uma abordagem histórico-teológico sem se descurar do enfoque das alianças, buscando o alcance filosófico decorrente dos diversos matizes na linha do tempo nas diversas literaturas.

De maneira mais específica, para a execução da pesquisa aqui pretendida, buscar-se-á, a nível de cenário bíblico, uma incursão no livro de Sofonias, fazendo-o de forma comparada entre vários doutrinadores, bem assim valer-se-á dos ensinamentos teológicos, especificamente na Teologia Cristã das alianças, tudo a concorrer para o desiderato já delineado.

Durante a abordagem, e por ocasião dos respectivos registros, serão elaborados capítulos específicos relativamente a cada tópico da pesquisa, buscando-se apontar as vantagens e desvantagens de cada um deles.

Após a apresentação do trabalho - tópico introdutório pretende-se que os tópicos seguintes tenham uma estrutura lógica, que apresente abordagens histórico-doutrinária ou seja, pesquisa qualitativa com forma de raciocínio dedutivo do tipo bibliográfico com historiografia na forma de coleta de dados.

Este trabalho está dividido em seis tópicos, onde o primeiro e o último tratam da introdução e as considerações finais respectivamente. Já no segundo tópico vamos entender o que vem a ser alianças divinas. No terceiro tópico analisaremos o livro de Sofonias: as circunstâncias da relação do livro, a mensagem e propósito, o dia do Senhor, o remanescente e a ira de Deus. No quarto tópico enquadraremos o livro no relacionamento com as alianças. No tópico seguinte, mergulharemos nos elementos de redenção para um Reino vindouro, a futura Jerusalém.

\section{SOBRE PACTOS E ALIANÇA}

Porque é tão difícil construir um entendimento fácil sobre as alianças e seus elementos? Em seu relacionamento com o homem Deus formalizou várias alianças. A questão é: como se relacionam entre si esses vários pactos? Alguma unidade liga as várias alianças espalhadas ao longo da história humana? As alianças devem ser vistas como compromissos distintos e sucessivos ou são construídas umas sobre as outras? Robertson 
(2002) procura responder as questões em direção ao caráter unificado das alianças bíblicas pois, segundo a sua ótica, nas alianças, Deus manifesta uma unidade estrutural e uma unidade temática. Para ele, cada aliança sucessiva é construída sobre um relacionamento anterior. As características do estabelecimento da aliança demonstram uma unidade. E o isso quer dizer? Respondo de forma singela: A aliança mosaica não anulou nem interrompeu a abraâmica. Esta continuou a funcionar ativamente depois da instituição da mosaica. A aliança abraâmica encontrou cumprimento básico no contexto da história da aliança mosaica. A aliança davídica não anulou nem interrompeu a mosaica. As alianças abraâmica, mosaica e davídica não suplantam umas às outras; elas se suplementam. Uma unidade básica as liga, a unidade da administração genealógica. Mas até onde se pode estender legitimamente o princípio de geração? Quantas gerações podem ser incluídas? O Salmo 105. 8-10 e Deuteronômio 7.9, responde pela eternidade dos pactos.

O Profeta Ezequiel 37.24-26, combina as alusões as alianças abraâmica, mosaica e davídica com uma palavra de profecia concernente às expectativas pactuais futuras de Israel. $O$ meu servo Davi reinará sobre eles; eles terão um só pastor (alusão a aliança davídica) andarão por meus juízos, guardarão meus estatutos e os obedecerão ( alusão a aliança mosaica) Habitarão a terra que dei a meu servo Jacó, na qual vossos pais habitaram ( alusão a aliança abraâmica )... Fareis com eles aliança de paz, será aliança perpétua ( alusão a nova aliança).

Todas as promessas de Deus se consumam na Nova Aliança. Jesus Cristo indica o momento da inauguração formal da Nova aliança por ocasião da instituição da refeição da aliança da Ceia do Senhor (Lucas 22.20). A questão é: como as administrações da aliança antes de Abraão se relacionam com as alianças posteriores? Obviamente essa tem sido por muito tempo uma questão importante remontando ao começo do cristianismo vez que toda a Escritura direciona para Cristo.

A Aliança com Noé fornece a estrutura preservativa pela qual o propósito de Deus de redimir um povo para si deve ser realizado e continua em vigor (Gen 8.22). Ademais, vemos na maldição proferida logo após a queda, o compromisso assumido por Deus no sentido de redimir um povo para si. O apóstolo Paulo faz referência a essa aliança em Romanos 16.20. Segundo o escólio de Robertson, ao longo do registro bíblico da administração da 
aliança divina, uma frase única se repete como sumário da relação pactual:" Eu serei o vosso Deus, e vós sereis meu povo", o que indica a unidade da aliança divina.

\section{REVISITANDO SOFONIAS}

Sofonias, profeta de Judá. Pouco se sabe a respeito deste profeta, cujo nome significa Jeová guardou. A longa genealogia de Sofonias (quatro gerações até Ezequias) sugere que ele era de linhagem real. Por que listar quatro gerações (outros profetas listam no máximo duas gerações). Talvez pelo fato de seu pai se chamar "Cuchi" as pessoas pudessem suspeitassem que Sofonias era de ascendência mista, com antepassados cuchitas. De fato, Sofonias menciona os cuchitas (Etíopes) duas vezes em sua breve profecia, o que sugere que ele, de fato, tinha raízes cuchitas. Evidencias internas indicam que o livro de Sofonias foi escrito em algum momento entre 640 e 612 a.C. Sofonias menciona o reinado de Josias e profetiza a queda de Nínive. Como Nínive caiu em 612 a.C. a profecia de Sofonias é anterior a este ano. Além disso a existência de práticas idólatras em Judá significa que o ministério de Sofonias começou antes da reforma de Josias por volta de 621 a.C (2 Rs 23).

No que respeita ao contexto histórico do livro de Sofonias, observa-se que o pai do rei Josias, o rei Amom, foi um homem ímpio, assim como o seu pai, o rei Manassés. Esta perversidade hereditária ajuda a explicar a tremenda idolatria que havia em Judá quando Josias herdou o trono em 640 a.C. Josias teve muito trabalho para esmagar a idolatria de Judá. Sacerdotes pagãos e ortodoxos estavam juntos à frente da adoração a Yahweh; ao mesmo tempo, eles se curvavam diante de Baal, Moloque e outros deseus pagãos. A leitura pública do livro da lei ajudou a multiplicar as reformas de Josias, pois o povo se arrependeu e destruiu seus muitos altares e a parafernália idolátra de Baal e moloque. Eles inclusive aboliram os falsos sacerdotes.

No livro de Sofonias encontramos o pensamento chave no versículo 1:14-16: o dia vindouro da ira de Deus. A destruição do "Dia do Senhor" estava prestes a acontecer. Portanto, o principal alvo de Sofonias era fazer um convite urgente. Ele recomendou com insistência que o povo de Judá buscasse Yahweh e somente Yahweh, com justiça e humildade. O propósito imediato era avisar o povo idólatra de Judá de que o juízo do Senhor logo iria chegar. 
O propósito final era levar um remanescente de todas as nações a confiar em Yahweh, pois o dia em que Seu juízo viria sobre toda a terra estava próximo.

O Reino de Judá deveria, aparentemente, ter aproveitado da experiência do cativeiro de Israel, pois Deus não Ihes mandou nenhum profeta durante o reinado do ímpio Rei Manassés, até Sofonias. O reavivamento durante o reinado de Josias depressa degenerou-se, com a ideia de tolerância, permitindo-se que todos escolhessem a sua religião. Isto Deus não poderia permitir e Sofonias foi enviado para chamar a atenção para o julgamento inevitável, a menos que um arrependimento completo se manifestasse.

A profecia de Sofonias é a mais compreensível dentre todas as enunciações proféticas, dirigidas a todas as nações debaixo dos céus, por assim dizer. A frase grande dia do Senhor, ou palavras semelhantes, é enfatizada em 1-3 e repetida nove vezes nos capítulos 1 a 3 . Nos tempos bíblicos, conquistar uma cidade por meio de cerco demorava meses e até anos; só um rei guerreiro realmente poderoso poderia dizer que era capaz de vencer uma batalha ou uma guerra em um único dia. O dia do Senhor era qualquer momento em que Ele viria a terra para punir seus inimigos ou salvar seu povo.

Mais do que todos os outros profetas, Sofonias vê a terra toda como o palco do governo universal de Deus. De todos os quadrantes, nações são escolhidas como exemplo para o Seu julgamento (2:4-15), mas Judá não aprendeu a lição. A profecia a respeito das quatro cidades da Filístis mostra que a profecia e a providencia são guiadas pela mesma mão. É verdade que Deus é amor. Porém, esta não é a descrição inteira do caráter de Deus. Ele também é ira contra toda a impiedade, onde quer que ela se encontre.

O livro de Sofonias pode ser dividido em duas partes um tanto desiguais. A primeira começa uma série de julgamentos (1.13.8); depois, segue-se uma promessa de restauração de um remanescente (3.9-20).

Os julgamentos enfocam Jerusalém, mas começam como julgamentos universais $(1.2,3)$ que vão se estreitando e acabam por se concentrar em Judá, o Reino do Sul de Israel (1.4-2.3). O livro, a seguir, transmite uma série de julgamentos sobre os vizinhos de Judá (2.4-15) antes de voltar o foco para Jerusalém, a capital de 
Judá e o centro de sua vida religiosa (3.1-7). Essa parte do livro de Sofonias conclui com mais um breve julgamento universal (3.8). Os julgamentos são transmitidos como "ais" e denúncias de pecados específicos transmitidos como se Deus estivesse falando diretamente com seu povo, usando o profeta como seu porta-voz. Os pecados variam de injustiça social e opressão a idolatria e apatia espiritual. A vinda do julgamento é anunciada em termos de "o Dia do Senhor", descritos em termos hiperbólicos de destruição e cataclismo totais. A mensagem, contudo, é temperada com a possibilidade de segurança e libertação nesse dia se "os mansos da terra" buscarem ao Senhor (2.3). Estes seriam protegidos e se tornariam um remanescente dos justos que não só seriam salvos, como também conheceriam o prazer e a prosperidade de Deus. Haveria restauração total para eles.

Cada um dos profetas menores tem alguma ênfase que os torna únicos. A ênfase de Sofonias é "o Dia do Senhor" (1.7), expressão que ocorre cerca de quatorze vezes nos quinze versículos seguintes, quer dessa forma quer como "aquele dia", "um dia", "o grande dia do Senhor" ou "o dia da ira do Senhor". A expressão é usada pelos profetas anteriores, como Amós (Am 5.18-20), Joel (I 1.15) e Isaías (Is 2.6-22), mas é Sofonias que a usa de maneira mais enfática e central em sua mensagem. Ao longo de Sofonias, a expressão torna-se aceita e amplamente entendida para o uso de escritores posteriores, com frequência em contextos apocalípticos.

\subsection{O REMANESCENTE}

A ideia de um remanescente justo a ser restaurado por Deus é absolutamente central para a profecia escrita do Antigo Testamento. Isaías 1.9 afirma: "Se o Senhor dos Exércitos não nos deixar algum remanescente, já como Sodoma seríamos". Isso salienta duas coisas:

- Os israelitas, às vezes, não eram melhores que as nações perversas que os rodeavam e realmente mereciam o mesmo julgamento delas.

- O relacionamento de Deus com Israel era diferente. Eles eram o povo escolhido por Ele para demonstrar seus propósitos para o mundo e foram estabelecidos pela aliança. 
Isso quer dizer que Deus escolhe preservar um povo por meio do qual Ele se faz conhecido. O padrão utilizado com Noé é semelhante: um remanescente tinha de ser preservado do dilúvio (Gn 8.21). Em Sofonias, o remanescente de Israel será virtuoso $(3.12,13)$, e Deus se regozijará ativamente por eles (3.17). A ideia de reunir do exílio, como em Joel 3.1,2 e Jeremias 31, também é uma atitude típica do Senhor.

\subsection{A IRA DE DEUS}

A ira de Deus, mais uma vez, é central para o entendimento da natureza do Senhor conforme revelada ao longo do Antigo Testamento. Em Sofonias, a ênfase é um Deus santo e uma cidade ímpia (3.5). A escolha de Deus de Jerusalém como sua cidade santa na qual seu Templo estaria situado significava que a cidade, em algum sentido, era seu lugar de moradia. Embora Ele fosse Deus de todo o mundo (1.2,3), Jerusalém era o lugar no qual o mundo maligno lhe era especialmente repugnante, uma vez que sua presença daria santidade especial à cidade. A descrição de Sofonias de lugares específicos da cidade (1.10-12) mostra que a ira de Deus não é apenas de natureza geral, mas é bem específica. A limpeza do Templo feita por Jesus mostra algo dessa ira (Mt 21.13). Em 3.8, a ira de Deus é voltada diretamente a todo o mundo porque fora dada oportunidade a todos para "[invocar] o nome do Senhor" (3.9).

A palavra profética (Deus destruirá todas as coisas de sobre a face da terra) é uma hipérbole. Embora ninguém mereça ser poupado, Deus irá preservar um pequeno remanescente de Judá e outras nações.

\section{SOFONIAS $E$ AS ALIANÇAS DIVINAS. REGRESSO ÀS PERGUNTAS SIMPLES}

A questão é: Sofonias faz referências explicitas a alianças? Argumenta-se que a palavra aliança não aparece nenhuma vez no livro de Sofonias. No meu sentir, vemos em Sofonias o mediador como símbolo da aliança divina. O mediador é o agente das consequências pois aquilo que ele faz traz sobre o povo consequências. O mediador em Sofonias é o Rei Josias. 
Para Sofonias, fica evidente que ele queria que os seus ouvintes pensassem no Deus Yahweh como Criador, Sustentador, Juiz do Cosmo, das Nações, Judá e Jerusalém. O Cosmo era o domínio sobre o qual Deus administra pactualmente seu governo soberano. Ele mantinha a sua aliança da criação.

O cerne do livro é a apresentação do chamamento para o ingresso na Aliança pois ainda era tempo da aceitação de novos ingressos e de egressos. Congrega-te, congrega-te ó nação que não tens pudor, antes que saia o decreto e o dia passe como a palha, antes que venha sobre vós a ira do Senhor, antes que venha sobre vós o dia da ira do Senhor. Segundo o escólio de Russell Shedd (2018), ser aceito na Aliança, implica submissão ao jugo dos mandamentos.

Ademais, Sofonias enfatiza as benção e maldições bem como as promessas de bênçãos e maldições. A maldição da aliança, da qual Moisés havia falado ao povo antes de atravessar o Rio Jordão e entrar na herança prometida, vinha no contexto de estipulações, pedindo devoção amorosa e obediência ao seu fiel Senhor da Aliança. A ênfase de Sofonias sobre a maldição da aliança era, sem dúvidas, apropriada, pois o livro de Deuteronômio que havia sido descoberto estava sendo lido e aplicado. O Profeta estava plenamente ciente de como as estipulações da aliança eram ignoradas, desobedecidas e rejeitadas. O Pecado da idolatria era uma violação do mandato espiritual da aliança da criação.

Uma condição é suficiente para entender a ira do Senhor, a Sua justiça: Deve-se compreender que o julgamento de ira executado sobre o povo da aliança tinha implicações cósmicas. $O$ povo possuía um grande mandamento pactual de cultivar a terra, sendo que este foi repetido por Noé. Mais tarde Abraão foi ordenado a ser uma benção para as nações. Assim, dentro da teologia bíblica, o povo da aliança tem um papel central no universo entre as nações, entre si como uma comunidade da aliança composta de agentes que creem e estão sob a direção e o domínio soberanos de Deus.

De algum modo, Sofonias chama a atenção para de outras nações sobre a ira do Senhor: o povo dos quereteus, Canaã, a terra dos Filisteus. A Etiópia. A Assíria.

Em Sofonias não existe proposta de nova aliança pois a última aliança do antigo testamento foi em Davi, entretanto como Deus permaneceu fiel, Ele chama o seu povo para cumprir as alianças anteriores a Davi e um anúncio da Aliança perfeita em 
Jesus Cristo, ou seja, a Aliança da Graça. Aqui entra a revelação messiânica em Sofonias, que se materializa na Futura Jerusalém.

A Aliança da graça está manifesta na expressão - naquele tempo - ou seja a presença de Deus no meio do seu povo também é um símbolo dessa aliança (3:17).

Observamos uma conexão entre as revelações nas alianças pois em Sofonias a Nova Jerusalém completa as promessas materializadas em todas as alianças. A ideia no Antigo Testamento era que a presença de Deus estava circunscrita no tabernáculo, porém, na aliança perfeita esse espirito estará no redentor e não em um lugar circunscrito. Deus vai até o povo. Deus era limitado e inacessível ao povo e agora está acessível a todos os que se renderam ou se arrependeram. Em Sofonias isso está claro na futura Jerusalém.

Em Sofonias o povo é chamado a olhar para a aliança de Abraão, por terem sido escolhidos e ele materializa as bênçãos e as futuras bênçãos. O povo deveria olhar para a benção e foram esquecidos por causa do pecado, pois a promessa era para que as nações fossem abençoadas por meio deles.

\section{O DESPERDÍCIO DA EXPERIÊNCIA E DA FONTE DE OBSERVAÇÃO ÚLTIMA DO PROFETA SOFONIAS E OS ELEMENTOS REDENTIVOS DE UM REINO VINDOURO}

Boaventura de Sousa Santos nos ensina, na sua Crítica a razão indolente, que a observação empírica dos fatos é instancia de observação última. Ele faz uma crítica sobre o desperdício da experiência, de sorte que as profecias se enquadram neste contexto de observação última e seu desperdício por um povo habituado a transformar silêncio em sussurros e ressaltos insignificantes, em preciosos sinais de desorientação. Diria, o desperdício da experiência ou da fonte de observação última do profeta.

O argumento central do capítulo terceiro de Sofonias é que existem elementos de redenção para a futura Jerusalém. Penso na transformação da mensagem do profeta de emancipatória para regulatória. Entre as ruínas que se escondem atrás das fachadas, podem pressentir-se os sinais, por enquanto vagos, da emergência do arrependimento e da congregação, antes do decreto do dia da ira. Ai da rebelde e manchada, da cidade 
opressora que não ouve a voz, não aceita o castigo e não confia no Senhor.

A transição requerida por Deus e materializada pelo profeta tem várias dimensões que evoluem em ritmos desiguais: arrependimento; resigna-te no castigo e confia no Senhor. A transição ocorre entre o conhecimento prudente do pecado e a confiança no Senhor após o arrependimento. A transição societal é menos perceptível mas emancipatória. Congrega-te, diz o profeta no capítulo segundo, em outras palavras, transforma-te em outras tantas estratégias regulatórias, buscai o Senhor, mas como nação através do teu mediador, o rei Josias.

Apesar dos príncipes injustos, dos juízes lobos, dos profetas arrogantes, dos traiçoeiros e sacerdotes profanos, o Senhor é justo em meio aos resíduos e ruínas de fragmentos aponta para a futura Jerusalém, onde dará lábios puros aos povos para que todos invoquem o nome do Senhor.

Diz Santos (2007) que recuperar a esperança significa alterar o estatuto da espera. Deixarei no meio de ti, um povo humilde e pobre, que confia no nome do Senhor. O remanescente, o realismo desesperado de uma espera que se permite lutar pelo conteúdo da espera, a possibilidade de resistir e a evidência da inevitabilidade, o remanescente de Israel não cometerá iniquidade; não proferirá mentira nem na sua boca se achará língua enganosa.

Sofonias inicia o versículo 17 do capítulo 3 com a certeza ou a consciência cartográfica do caminho que vai sendo percorrido pelas lutas do povo remanescente: O Senhor Deus está no meio de ti, poderoso pra te salvar. Ele se deleitará em ti com alegria, te renovará no seu amor; ele se regozijará em ti com júbilo.

\section{CONSIDERAÇÕES FINAIS}

O presente artigo procurou analisar a relação entre o livro de Sofonias e as Alianças. Urge superar as ausências da expressão aliança em seu texto o que foi o plus dos estudos de teólogos sobre o livro.

O artigo aborda o tema das alianças de forma exaustiva para o livro de Sofonias, que é exatamente a compreensão do amor e justiça de Deus, devidamente diferenciado do conhecimento de Deus. É importante refletir que para os cristãos em santificação, o conhecimento dos pactos divinos é relevante para o entendimento do sofrimento e da perseverança e não são 
mais as trevas que os castigam, mas a acuidade da luz espiritual que atravessa a inteligência e o faz sentir a angústia da sua falta. A luz que tortura o cristão culpado é a luz do desenvolvimento da sua santificação. A dor moral é a forma maior de expurgar o pecado na concepção aqui estudado. À medida em que vamos adquirindo sabedoria (conhecimento de Deus e de seus pactos) e compreendemos o temor ao Senhor sofremos menos. A dor suprema a cada dia é aliviada pela compreensão e conhecimento de Deus.

A sabedoria é o conhecimento elevado ao mais alto nível de moralidade é o êxtase da compreensão de Deus. Ora, conhecer a forma de relacionamento com Deus através dos pactos e como eles são evidenciados nos Profetas é o ponto nodal da reflexão exposta na pesquisa.

No segundo tópico, em que o conceito de alianças foi estudado é possível observar a forma prática e empírica de relacionamento entre Deus e os homens.

No terceiro tópico estudamos o relacionamento de Sofonias com as alianças e para uma melhor compreensão abordamos alguns pontos controvertidos que foram esclarecidos.

Portanto, por derradeiro concluímos que o livro de Sofonias está permeado pelos pactos divinos.

\section{REFERÊNCIAS}

BAUMAN, Zygmunnt. Legisladores e Interpretes. Tradução Renato Aguiar. Rio de Janeiro: Zahar, 2010.

BAVINCK, Herman. Dogmática Reformada, organizada por John Bolt e traduzida por Vagner Barbosa. vol. III. São Paulo: Cultura Cristã, 2012.

BERKHOF. Louis. Teologia Sistemática. Tradução Odayr Olivetti: $4^{a}$ ed. rev. São Paulo: Cultura Cristã, 2012.

BÍBLIA Thompson: Letra grande/ compilado e redigido por Frak Charles Thompson: tradução João Ferreira de Almeida. São Paulo: Vida, 2014. 
PIPER, John. $\mathbf{O}$ poder purificador de se viver pela fé na graça futura. Tradução Valdemar Kroket. São Paulo: Shedd Publicações, 2009.

ROBERTSON, O. Palmer. O Cristo dos Pactos: uma análise exegética e teológica das sucessivas alianças bíblicas e do seu papel no desenvolvimento da revelação de Deus. Traduzido por Américo Justiniano Ribeiro. São Paulo: Editora Cultura Cristã. 2002.

SANTOS, Boaventura de Suza. A crítica da razão indolente. $\sigma^{\mathrm{a}}$ ed. São Paulo: Cortez. 2007.

SHEDD, Russell P. O homem em comunidade: a Solidariedade da Raça na Teologia de Paulo. Tradução de Marcio Loureiro Redondo. $2^{a}$ ed. São Paulo: Vila Nova. 2018. 